Brazilian Party Formation:

Questions of Ideology, Party

Labels, Leadership, and Political

Practice, 1831-1888

\title{
Formação dos Partidos Brasileiros: questões de ideologia, rótulos partidários, lideranças e prática política, 1831-1888
}

Jeffrey D. Needell

Professor no Departamento de História da Universidade da Flórida

(College of Liberal Arts \& Sciences/

UF - Flórida/EUA)

e-mail: jneedell@ @istory.ufl.edu

\section{Resumo}

Apresento aqui uma resposta aos comentários de R. Salles e M. Dantas, em que se discutem o uso da terminologia gramsciana, as diferenças ideológicas entre os partidos, os nomes dos partidos durante a Regência e o Segundo Reinado e a prática política nos âmbitos provincial e nacional. Argumento que os saquaremas não eram um partido hegemônico, seus líderes eram orgânicos, as diferenças entre os partidos eram essenciais em certos pontos e o uso dos nomes dos partidos no texto discutido decorre da utilização e significado coevos. Esta réplica também aborda as divergências fundamentais que envolveram o Ato Adicional, o significado da legislação centralizadora do Regresso e, por fim, os êxitos e limitações tanto do poder do Estado como da mobilização política provincial em influir no governo provincial, na política nacional e na prática política imperial.

\begin{abstract}
This is a response to comments by R. Salles and M. Dantas, and discusses the use of Gramscian terminology, ideological differences between the parties, party names used during the Regency and Second Reign, and political practice at the provincial and national levels. It argues that the saquaremas were not a hegemonic party, that their leaders were organic, that the differences between the parties were fundamental on certain points, and that the use of party names in the text debated derive from contemporary usage and meaning. The response also comments on the fundamental differences involved in the Additional Act, on the significance of the reactionary centralizing legislation, and, finally, on the success and limitations of both State power and of provincial political mobilization in affecting provincial government, national policy, and imperial political practice.
\end{abstract}

\section{Palavras-chave}

práticas políticas, monarquia, escravidão, poder legislativo, debates parlamentares, liberalismo

\section{Keywords}

political practices, monarchy, slavery, legislative power, parliamentary debates, liberalism 
1

SALLES, Ricardo. Notas de um debate. Comentários sobre o texto de Jeffrey Needell Formação dos partidos políticos no Brasil da Regência à Conciliação, 1831-1857. Almanack Braziliense, São Paulo, n.10, p.51, nov.2009.
Em resposta aos comentários de meus colegas durante a mesa-redonda, achei melhor tratar dos pontos mais relevantes, de maneira a contemplar as questões e os comentários do público. Aproveito então, aqui, a oportunidade oferecida pela Almanack Braziliense para responder mais extensa e detalhadamente alguns dos assuntos levantados em nosso encontro e em comentários entregues por escrito pouco antes do fórum. Vou fazê-lo na ordem dos comentários, agrupados conforme os interlocutores, começando pelos do Dr. Ricardo Salles.

\section{Ricardo Salles}

Lendo os comentários feitos por Salles, encontrei muito pouco de que discordar na maior parte deles. Pelo contrário, em termos de perspectiva geral e de boa parte de nossa compreensão e análise do período, acredito que nossas posições são praticamente as mesmas. Entretanto, há uma considerável divergência entre nós em relação à adequação da análise gramsciana defendida por ele (e, antes dele, por llmar Rohloff de Mattos), bem como em relação à análise baseada em arquivos dos pormenores, dos processos políticos e das biografias, centrais na minha abordagem. Isso será mais bem explorado em minha tentativa de resposta a uma frase (ou mais) de seu item 4.b):

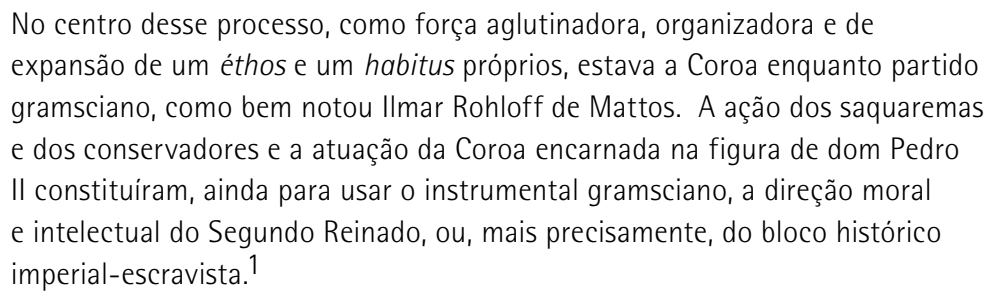

Por mais que eu aceite a necessidade de se compreender o contexto e os interesses socioeconômicos, assim como a maneira em que ideologia e interesses materiais influenciam-se mutuamente, e embora admire as idéias de Gramsci e reconheça o potencial de seu trabalho para o nosso, reluto em aceitar a idéia de que hegemonia e ideologia ou partido hegemônico, conforme entendo os conceitos de Gramsci, tenham prevalecido no periodo e no local em questão. Devo destacar, de início, que no final da década de 1980, quando elaborei uma história intelectual do pensamento social conservador brasileiro (1830-1940), esperava encontrar algo próximo a uma ideologia hegemônica; e esperava fazê-lo estudando o uso que se fez dos conceitos de história, Estado e raça ao longo das gerações, por meia dúzia de importantes intelectuais. Contudo, a investigação da especificidade da história política do período em que o Estado brasileiro foi debatido e reestruturado me convenceu que os conflitos, particularmente políticos e ideológicos, eram mais complexos e contingentes. Hegemonia, como eu a entendo, não significa o simples controle da sociedade por uma classe, mas uma situação em que todas as outras classes aceitam o projeto ideológico da classe dominante como justificativo de seus próprios interesses e adequado a eles. 0 consenso espontâneo entre elas é fundamental. Apesar de os saquaremas, por exemplo, terem triunfado sobre os luzias na década de 1840, o Partido Liberal resistiu e recuperou sua força, sem grandes alterações em sua ideologia, ao longo da década seguinte. Em resumo, não aceitaram a ideologia ou o Estado ligados aos saquaremas; contestaram-nos. Para que a hegemonia fosse atingida, Gramsci não 
esperaria uma ideologia em que todos os atores políticos a reconhecessem como "natural"? A ideologia dos saquaremas certamente não era admitida como tal: ela foi explicitamente contestada pelos Liberais, que propunham uma visão significativamente distinta tanto do Estado como da sociedade. Mais intrigante, no que diz respeito à questão crucial da escravidão, os saquaremas foram deliberadamente contrariados pelo monarca.

Permitam-me desenvolver essa idéia. Os exaltados e seus herdeiros, T. Otoni e Tavares Bastos, por exemplo, mantiveram basicamente a mesma crítica sobre as posições dos saquaremas ao longo das décadas; eles certamente não aceitavam essas idéias como "naturais". Aspectos básicos, desde a legislação regressista até a concepção do papel do imperador, continuaram sendo alvos de seus panfletos e discursos; de fato, durante a década de 1860, as críticas aumentaram. Em um nível mais particular, embora eu concorde que ambos os partidos e seus seguidores aceitavam a escravidão como um componente "natural" da ordem social, isso tanto contradiz a idéia de que essa posição era especificamente parte da ideologia saquarema como vai de encontro à idéia de que ela era parte integrante da posição do monarca, que era reconhecidamente abolicionista e, conforme tentei demonstrar em meu livro, foi a figura central na promoção da Lei do Ventre Livre na década de 1860 até seu triunfo em 1871. Isso toca em um aspecto crucial da análise de Salles e de Rohloff de Mattos; para eles, e vou parafrasear aqui, a Coroa operava como um partido gramsciano, compunha com as ações dos saquaremas e dos Conservadores, encarnava na figura de Dom Pedro II e provia liderança moral e intelectual para o Segundo Reinado, constituindo o "bloco histórico imperial-escravista". Como se poderia aceitar o imperador como integrante de um partido gramsciano unificado que incluia os saquaremas, quando documentos publicados e inéditos do período demonstram que o monarca foi bem-sucedido na luta para promover a abolição, ao passo que os saquaremas perderam a amarga luta para impedir que o imperador impusesse seu projeto?

Salles observa essa divergência entre nossas análises e perspectivas com grande sensibilidade e cuidado no parágrafo seguinte. Ele compreende minha escolha, mas não necessariamente concorda com ela, por uma "narrativa mais factual dos eventos desse processo histórico", destacando que "permanece uma certa frustração" em relação a minha "falta de diálogo com a interpretação de Rohloff de Mattos". Salles deseja mais discussão sobre o tema, em particular por perceber (se eu puder arriscar uma impertinência) um tipo de afinidade intelectual entre ele, seu mentor e mim, no emprego que faço de "intelectual orgânico" para caracterizar a relação dos saquaremas com as oligarquias fluminenses que lideravam e representavam. Utilizei "orgânico" para descrever os fundadores e os líderes tradicionais do Partido Conservador, bem como seus herdeiros, pois, conforme entendo Gramsci, esse é o termo apropriado para intelectuais que provêm de um grupo social e representam seus interesses; e isso descreve as origens e/ou os interesses dos homens sobre quem escrevo. Entretanto, é claro que é possivel existir intelectuais orgânicos e eles podem ambicionar uma hegemonia e uma ideologia hegemônica, e ainda assim falharem. É isso que, na verdade, ocorreu com o partido Conservador e sua liderança tradicional, como defendo em meu livro. Aqui, os comentários de Salles durante a mesa-redonda (e no item 3 de seus comentários) são extremamente úteis: ele apontou a grande diferença entre o que se 
pretende fazer, o que se faz e o impacto daquilo que se fez. Meu livro descreve os objetivos, ações e idéias dos fundadores do partido, bem como a maneira em que o Estado que ajudaram a definir e dirigir assumiu relativa autonomia nas mãos do monarca, que se voltou contra eles e seus interesses com um sucesso fatal.

Acredito que Salles possa estar equivocado ao me atribuir a idéia de que toda a liderança conservadora era orgânica. Para mim, discutindo sobre os ministros Conservadores moderados do período da Conciliação e da pós-Conciliação de meados de 1850 e 1860, fui explícito ao distinguir aqueles Conservadores conduzidos ao poder pelo monarca (antigos saquaremas, como Paraná, que tinham se tornado mais pragmáticos, e homens menos ideológicos e mais moderados que serviam à Coroa, como Paranhos, Caxias etc.) daqueles que recusaram ministérios após 1853 e atacaram tanto a Conciliação e o que consideravam oportunismo dos gabinetes moderados quanto a Liga Progressista (saquaremas como Eusébio, Rocha etc.). Os saquaremas e seus herdeiros, a liderança ideológica tradicional e os chefes políticos articulados às principais regiões fluminenses que seguiam o partido eram claramente orgânicos e, em sua maior parte, permaneceram em um dos lados do partido; os homens do imperador, aqueles que preferiam Ihe servir ao invés de servir à liderança do partido ou à sua ideologia, estavam no outro lado. Essa é a diferença entre o triunvirato saquarema e seus herdeiros e coligados, tais como Paulino José Soares Filho, Andrade Figueira, Justiniano José da Rocha etc., e aqueles homens como Caxias, Rio Branco e Nabuco de Araújo. É o tipo de coisa que ajuda a explicar por que alguns dos moderados estariam dispostos a deixar o partido Conservador definitivamente (por exemplo, Nabuco de Araújo, Zacarias e outros, que deixaram o partido no início da década de 1860 para formar a Liga e depois se tornaram Liberais). É precisamente minha abordagem do passado, em que a análise factual é fundamental para a narrativa do processo histórico, que revela essas distinções e seus importantes impactos nas reviravoltas da história política. É verdade que esses homens tinham muito em comum, em termos de interesse de classe, devoção à monarquia e compromisso em servir ao Estado. Entretanto, a menos que se entendam suas diferenças cruciais na abordagem do partido, Estado e monarquia, não acredito ser possivel compreender o processo histórico e a natureza da política imperial - e essas eram minhas metas. É significativo que Salles possa descrever 1871 e 1888 associados à preeminência Conservadora; em meu livro, busquei demonstrar como 1871 foi uma derrota para a liderança tradicional e ideologia do partido. Em meu próximo livro, espero demonstrar o mesmo em relação a 1888. As leis abolicionistas desses dois anos foram triunfos dos reformistas no interior do partido e daqueles que se juntaram a eles sob pressão política. Esses foram, com certeza, tours de force políticos, mas não triunfos conservadores; ao menos, não se associar "Conservador" com suas origens e lideranças históricas. Na medida em que isto é levado em conta, as leis de 1871 e de 1888 foram sinais de derrota do partido, ferindo de morte a tradição, a ideologia e os interesses saquaremas.

\section{Implicâncias?}

\section{Por que reacionários e não regressistas?}

Eu utilizei a palavra "reactionary" como a melhor tradução de "regressista". Ambas se relacionam a um retorno político a uma posição ameaçada 
ou perdida, e, no sentido em que publicistas como Evaristo usaram o termo para fazer referência a Vasconcelos e seus associados, trata-se de uma tentativa de um liberal de atacar outro por retornar a uma posição politica que eles haviam contestado anteriormente (o Estado e o monarca fortalecidos do Primeiro Reinado). Segue a definição do Oxford English Dictionary, a qual fornece as analogias históricas que também achei interessantes:

\begin{abstract}
A.s. Uma pessoa tendente ou favorável à reação, esp. alguém que é contra reformas politicas ou sociais radicais e favorável ao retorno à situação anterior. Nos primeiros exemplos, significando ou traduzindo réactionnaire do francês, um oponente da Revolução Francesa; no uso posterior do Marxismo, denotando freq. um oponente do comunismo.
\end{abstract}

1799 Reply L. N. M. Carnot to Rep. Conspiracy 18th Fructidor 149 Quando no Diretório, eu contribui para livrá-lo de novos perigos, onde os mesmo vilões, então agindo como insubordinados reactionaries [Fr. Comme réacteurs], haviam se infiltrado. 1799 tr. F. D'Invernois Hist. \& Polit. Surv. Losses French Nation 11 0 reino dos Moderados... deu origem ao que é chamado de reaction royale... Os reacionários reais [Fr. Les réactionnaires royaux] cometeram crimes dos quais a história das nações mais bárbaras não fornece exemplos. 1844 Southern Q. Rev. Jan. 93 Assim que o sistema de terror foi derrubado... a convenção... tinha dois grupos de inimigos com que lidar. Os violentos revolucionários opostos à reação e os violentos reacionistas (reacionários)... que desejaram conduzir rapidamente o governo de volta à monarquia.

Evaristo e outros moderados procuraram usar regresso e regressista justamente para indicar que Vasconcelos e outros que o apoiaram eram reacionários em relação às reformas liberais. De fato, Vasconcelos, que tinha sido intimamente associado à legislação de 1834, discutiu seus aspectos antes que fosse aprovada e, mais tarde, acabou por discordar completamente dela, trabalhando junto a Paulino José Soares de Sousa na "Interpretação" que com êxito a modificou. No ambiente liberal da Câmara, esse ataque dos inimigos de Vasconcelos era politicamente inteligente $e_{\text {, }}$ em relação à posição que ele e seus seguidores estavam definindo, não era um termo inteiramente inadequado. Deve-se recordar que Vasconcelos inicialmente ridicularizou o termo, julgando-o sem significado para o que ele tinha feito e estava fazendo. Posteriormente, como ocorrera com a terminologia da década de 1840 relacionada aos estadistas chamados de luzias e saquaremas, o termo passou a ser utilizado pelos dois lados.

\title{
Por que Partido da Ordem e não Terceiro Partido?
}

Segundo minha pesquisa, a idéia de um Terceiro Partido surgiu em meados da década de 1830, estreitamente ligada à desavença particular de Vasconcelos com os moderados. Não encontrei o termo associado ao partido que emergiu como maioria na Câmara em 1837. Empreguei "Partido da Ordem" porque os porta-vozes do partido da maioria assim se referiam explicitamente ao seu partido tanto em discursos como em seu periódico partidário, 0 Brasil. Salles encontrou o termo referindo-se a políticos pernambucanos, mas eu não. Membros do partido nacional utilizaram o termo para se distinguir de sua oposição, a quem queriam taxar de "anarquistas". Dei ênfase ao termo no título do livro porque parecia apontar para a maior ambição dos fundadores, líderes e herdeiros do partido: a manutenção e segurança da ordem política, social e econômica. 
NEEDELL, Jeffrey D. The Party of Order. The Conservatives, the State and Slavery in the Brazilian Monarchy, 1831-1871. Stanford: Stanford University Press, 2006, p.366, n.81 e p.371-372, n.41, para detalhes.

\section{Por que não conservadores a partir de mais ou menos 1840 e certamente para o gabinete de 1848-53?}

Em The Party of Order, tentei, nas pequenas e grandes questões, evitar o anacronismo, que tende a deformar a percepção do leitor em relação ao passado e à mudança ao longo do tempo. Enquanto "partido da ordem" aparece em discursos e em 0 Brasil no ano de 1844, "conservador, partido conservador" não. Eu os encontrei em fontes coevas apenas em 1855².

\section{Monica Dantas}

0 teor dos comentários de Dantas se assemelha a uma série de questões e pontos suscitados pelo meu texto. Na maioria das vezes, concordo com esses pontos. 0 que se segue, então, é uma resposta às questões ou aos pontos de que discordo.

A citação de Visconde de Albuquerque, utilizada freqüentemente para rejeitar a idéia de distinção ideológica entre partidos teve, por esse motivo, um infeliz impacto sobre essa historiografia. No entanto, ela pode também ser utilizada para tratar de um tema relevante sobre o Partido Liberal. Albuquerque, de fato, se assemelhava muito aos saquaremas quanto a seu histórico, seus interesses de classe e seu monarquismo. Assim, quando ele ou sua ala dos Liberais estavam no poder (isto é, os moderados, monarquistas liberais que dominaram o gabinete da Maioridade ou os gabinetes do Qüinqüênio Liberal), tenderam a defender a idéia de um Estado forte e as prerrogativas constitucionais do imperador. Contudo, foram também alvo de ataques repetidos da ala mais radical e reformista do partido, ligada a homens como Teófilo Otoni. Essa é, realmente, uma das razões por que esses gabinetes foram efêmeros: tinham dificuldade em garantir o apoio da Câmara. Durante o Qüinqüênio, em particular, a frustração dos deputados liberais reformistas com seus gabinetes era notável e levou à crescente radicalização naqueles anos. 0 que teria sido mais exato (e honesto) seria o ditado "Não há nada mais parecido com um saquarema que um Luzia como o Visconde de Albuquerque no poder". Luzias como Otoni nunca foram conduzidos ao poder justamente porque o imperador não confiava neles. Esses radicais ou reformistas eram geralmente marginalizados, uma minoria na Câmara, raramente significantes nos gabinetes e sempre opositores do regime reconstruido e firmado pelos saquaremas. Em uma frase, os saquaremas venceram, mas não o fizeram incontestes, e um liberalismo mais radical se fez presente em 1848, em 1860 e em 1868-69, nas derrotas, nos panfletos, na mobilização política e no manifesto de 1869. Eles perderam, mas não foram cooptados nem cederam. Eles não eram tão parecidos assim com os saquaremas.

Eu não tive o prazer de analisar o trabalho de Miriam Dolhnikoff. No entanto, pelo menos nesse breve resumo de seu trabalho, devo admitir algumas dúvidas. A essência de 1834, conforme a entendi, era a idéia de uma mudança substancial de poder do centro para as provincias. 0 cerne da Interpretação e do 3 de dezembro, como os compreendi, foi uma reação àquilo, defendendo, ao contrário, a reafirmação da autoridade central sobre as províncias e, por meio destas, sobre os municípios. Fundamental para isso era a definição de um poder sobre todos radicado no centro. Essa é uma das razões por que os Liberais, particularmente a ala reformista radical, permaneceram críticos do status quo e invocavam a Federação. Não há contradição entre isso e a criação de assembléias provinciais. Quanto ao fato de o Conselho de Estado ter sido tranquilamente extinto, eu teria que 
rever os debates. Deve-se lembrar que, na época, na terceira legislatura de 1834-37, reforma era a sua raison d'être e havia um temor geral entre os moderados de ambas as alas de que Dom Pedro, duque de Bragança, tendo assegurado a monarquia portuguesa para sua filha, Maria da Glória, poderia estar na eminência de retornar ao Brasil para garantir a monarquia a seu filho. Poderia muito bem ser que, nesse contexto particular de uma crescente onda de reforma e de medo de restauração, houvesse alguns moderados prontos e ansiosos para defender a instituição ligada ao absolutismo declarado do primeiro imperador. Entretanto, uma vez que o perigo de retorno de Dom Pedro terminou, aqueles que acreditavam na necessidade da monarquia e de sua força começaram o processo de reação. Isso culminou na maioria regressista de 1837, que foi sucedida pela quarta e ainda mais consistentemente legislatura regressista de 1838-41, que não apenas trouxe a legislação da Interpretação e do 3 de dezembro, mas também a restauração do Conselho, no final de novembro de 1841 (dez dias antes do 3 de dezembro). Essa legislatura diferia, então, da terceira, que havia oscilado, de maneira dramática, em torno do tema do governo monárquico centralizado, desde a reforma de 1834 até a reação de 1837, o que parece minar a idéia de "relativa tranqüilidade". Na verdade, o fato de que a Câmara em 1834 extinguiria o Conselho de Estado e depois, em sessão conjunta, votaria pela manutenção do Poder Moderador, sugere que há mais drama e inconstância envolvidos.

A idéia de que grande parte do Ato Adicional foi deixada intacta ou de que o partido de oposição, uma vez no poder, viu a necessidade de algumas revisões do Ato, são percepções colocadas aqui para sugerir a existência de uma razoável base comum entre os dois partidos acerca dessas reformas. A respeito dos pontos mencionados, isso pode estar correto, mas questiono se os pontos mencionados em relação ao Ato Adicional (aqueles intactos, aqueles revistos) são tópicos de grande importância. Afinal, a legislação de 3 de dezembro permaneceu uma bandeira dos Conservadores e um alvo dos Liberais ao longo do Segundo Reinado, e suas revisões foram feitas apenas em pequenos passos e com grandes hesitações. Há também o furor que irrompeu quando Paraná procurou empreender a reforma judicial durante a Conciliação. Em suma, considerar essenciais menos essenciais como base para sugerir que a distância entre os partidos não era tão grande parece problemático. Essa idéia é enfraquecida ainda mais pelos debates políticos (sustentados por alguns dos mais notáveis panfletos do Segundo Reinado, particularmente na década de 1860) entre os partidos sobre assuntos cruciais como: 1) o papel do imperador e sua relação com o gabinete, 2) o papel do Estado no governo local, 3) reforma eleitoral (desejada por ambos os partidos, mas por diferentes razões; e, portanto, com diferentes reformas em mente - Liberais queriam garantir representação minoritária, os Conservadores queriam limitar a intervenção do gabinete e aumentar as restrições sobre os subordinados) e, 4) o papel do Estado no desenvolvimento econômico (após 1850). Eu concordaria, como sugere Dantas, que as diferenças em relação à escravidão, tanto ao tráfico quanto à própria manutenção dos cativos, eram imperceptiveis entre a maioria de ambos os partidos. Nabuco deixa claro que o anúncio da Liga sobre a necessidade de se discutir a abolição foi um choque para os dois partidos, e a história do Abolicionismo (1878-1888) evidencia que a maioria de ambos era enfaticamente contra a abolição. 
Em um ponto menos importante, acredito que Dantas esteja equivocada na leitura de meu texto ao dizer que a oposição buscou colocar o imperador no trono em 1840 para evitar a aprovação da lei de 3 de dezembro; eu sugeri que eles buscaram assumir o poder antes que a lei fosse aprovada, pois temiam, mais tarde, ser alijados do poder se os outros estivessem no poder com o 3 de dezembro nas mãos. Concordo com a interpretação de Dantas sobre a relação entre o 3 de dezembro e a "eleição do cacete". Isto é, que a oposição usava de grande violência para garantir resultados eleitorais justamente porque não tinha ainda 0 3 de dezembro em mãos. A nova lei facilitou a fraude eleitoral, evitando os escandalosos niveis de violência que eram tão anormais, que o novo Conselho de Estado pressionaria o imperador a anular os resultados (uma das provocações que levaram às revoltas de 1842). Uma vez instaurada a lei, tanto a ala moderada do partido de oposição como o partido do Regresso poderiam utilizar o diploma de 3 de dezembro para criar maiorias dóceis na Câmara, e o fizeram, como apontei em meu livro. 0 alargamento do Estado foi conveniente aos regressistas e à ala moderada da oposição, e ambos começaram a tirar daí proveito na década de 1840, estabelecendo uma nociva tradição que ajudaria a solapar a legitimidade do governo representativo.

Em resposta aos comentários de Dantas acerca das cartas de Mota enviadas do Piauí, isto é, que essas não existiriam se o poder do Estado fosse tão grande como sugerido na lei de 3 de dezembro, eu responderia que Mota estava se queixando da pressão; não estava cedendo a ela. Ele estava escrevendo para o ministro da Justiça porque entendia que os saquaremas provinciais eram importantes para o ministro e por estar buscando conselho, apoio e orientação. 0 que ele conseguiu foi aliviar as dificuldades de sua posição, já que Eusébio decidira que seria melhor garantir o apoio local que impor a "missão civilizadora". (Mota não foi punido ou desprezado posteriormente por Eusébio; ele foi designado para outras posições e os dois se tornaram parentes). A questão mais importante, certamente, é a do poder do Estado; e os saquaremas compreenderam isso com clareza, garantindo-a por meio da negociação com a elite local. Eles priorizaram uma intervenção esclarecida, mas abaixo da sobrevivência do Estado, a qual demandava apoio e votos locais. Aparentemente, Mota foi afastado (assim como Honório, nos outros casos que citei) para preservar o apoio eleitoral local. 0 fato de que o Estado tinha poder para efetivar suas políticas não significava que seria sempre prudente utilizá-lo. E se esse poder fosse ineficiente, não teria sido motivo de tanta preocupação para a oposição radical/reformista. Acredito que se tenha algo parecido em resposta à questão do porquê os radicais e os reformistas do partido de oposição teriam sido eleitos durante o Qüinqüênio Liberal, se eles evidentemente se opunham aos moderados (dos gabinetes de oposição) da época, e os gabinetes eram tão fortes em sua capacidade de intervenção e fraude eleitoral. Mais uma vez, trata-se, sem dúvidas, de uma questão de negociação e de realidades locais. Os gabinetes precisavam alcançar a oposição local a seus inimigos nas eleições, para garantir que formariam a maioria. Não podiam criar moderados no âmbito local naquele momento, tinham que trabalhar com os membros da oposição disponiveis. Nesse período, logo em seguida à polarização de meados e finais da década de 1830 e começos da de 1840, isso significava sem dúvidas que muitos ou até a maior parte da oposição no nível local estavam ligados aos militantes 
da ala esquerda da oposição. Os gabinetes os apoiavam nas eleições, faut de mieux, para vencer os regressistas. Depois, com esses homens assentados na Câmara, eles tinham que enfrentar suas críticas, ataques e frustrações. Como ocorria com os gabinetes regressistas, a obtenção e a manutenção do poder do Estado, em um meio político de guerra partidária, tinham prioridade máxima - mesmo se isso significasse apoio incerto na Câmara.

Essa idéia de realidades locais no âmbito provincial e de negociação com os gabinetes é algo congruente com o pedido de Dantas por pesquisas que explorem o funcionamento da politica e a justiça provinciais. É por isso que acho tão atraentes esse pedido e suas sugestões acerca de como as coisas devem ter realmente funcionado. Barman, anos atrás, me chamou a atenção para o papel fundamental da assembléia provincial fluminense na mobilização e articulação dos regressistas, e eu procurei abordar essa questão em meu livro; aqui, novamente, Dantas invoca pesquisas similares para as outras províncias.

Em resposta à menção de Dantas sobre as origens liberais da reforma eleitoral de Honório, eu concordo, e acredito que apontei isso no livro. A questão, ao menos para mim, é por que isso surge novamente na Conciliação. Tanto os regressistas (como Vasconcelos e Honório) quanto a oposição tinham demandado reforma eleitoral de vários tipos na década de 1840. Mas, conforme entendo isso, Honório viu essa reforma em particular como algo que poderia ser utilizado para enfraquecer os partidos e favorecer o poder do gabinete; e o imperador também a aceitou para seu próprio bem ou, como era a intenção de Honório (na minha visão), para enfraquecer os saquaremas. Aqui, devem ter se misturado os instintos de autopreservação e de vingança do presidente do Conselho. Lembre-se que os saquaremas tinham acabado de forçar a derrota do gabinete de Paraná na reforma judicial, no primeiro teste do poder do gabinete contra os saquaremas na Câmara e na sociedade civil. De fato, deve-se recordar que a reforma judicial desencadeara a reação articulada dos grandes plantadores de café do Vale do Paraíba, sob a liderança do clã mais poderoso de Vassouras, a família Teixeira Leite - uma reação coordenada e sustentada pelo próprio Eusébio, conforme demonstra meu livro. A reforma eleitoral fazia sentido tanto para levar adiante o fortalecimento da posição do gabinete quanto para restringir o papel dos saquaremas. Nem o presidente do Conselho nem o imperador teriam ficado confortáveis com a derrota inicial, dado seus temperamentos e as grandes questões de pode em jogo. 0 presidente do Conselho teria percebido que tinha que reverter a derrota e que a reforma eleitoral cumpriria bem esse papel. Essa reforma minou diretamente a força eleitoral dos saquaremas ao impedir o uso de listas provinciais organizadas pela liderança do partido na Corte. Ela também iria, ao enfraquecer drasticamente a intervenção dos partidos e ao rebaixar a disputa eleitoral para o "círculo" local, forçar as influências locais a concorrerem umas com as outras, uma disputa de poder em que as vantagens decorrentes da influência do gabinete se tornariam relativamente mais fortes.

Dantas se questiona se a descentralização do Ato Adicional, bem como a mobilização e a articulação das elites provinciais, não teriam levado à intervenção daquelas elites para o nivel nacional, contra os interesses dos partidos nacionais ou do próprio imperador. Não há dúvidas de que algo dessa natureza ocorreu na luta pernambucana com o gabinete saquarema no período de 1848-53. Ao menos a ponto de forçar favores e patronagem, 
os deputados da província organizaram um bloco forte o suficiente para pressionar o gabinete (discuto isso no livro em termos da crescente frustração do gabinete).

A acomodação de interesses provinciais dentro dessas linhas gerais parece bem provável de acordo com o que vi. Contudo, pela própria natureza da organização no âmbito provincial, intervenção em assuntos políticos mais amplos não parecia muito plausivel; eles teriam que ter cooptado o gabinete e controlado sua direção, mas não o fizeram. Ao contrário, o que observei nos gabinetes posteriores a 1853 foram ministros indicados pelo imperador em negociações com os seus presidentes do Conselho; embora houvesse ministros claramente representando os blocos de interesse regionais, ou alas de um ou dos dois grandes partidos, a grande política permaneceu nas mãos do monarca e dos ministros que ele privilegiava por meio de repetidas indicações. Aplaudo a idéia de explorar isso mais a fundo, é claro. Seria importante saber em que medida as negociações relacionadas à formação de gabinetes e às subseqüentes conversações dos gabinetes com as delegações da Câmara envolveram os blocos organizados no nível provincial e, assim, articulados com as delegações provinciais na Câmara. No entanto, desconfio que isso nos dará uma idéia de como a patronagem funcionava e influenciava o governo de gabinete (efetivando, retardando ou travando), e não como ela moldou tal governo ou o originou. Por esta razão não vejo isso como um processo que contradiga minha perspectiva de que o peso do monarca e a autonomia do Estado cresceram firmemente ao longo do Segundo Reinado. 0 monarca e o gabinete poderiam usar e usavam a patronagem para garantir votos nas politicas que eles desejavam implementar. Eles podem ter sido forçados a trocar patronagem por esses votos, mas aparentemente não eram forçados a aceitar o controle em troca de apoio. Ao contrário, a negociação revela as complicações da política e o custo de se fazer negócio com a política. Se a questão mais importante é quem determinava a política do Estado nos assuntos mais relevantes, internos e externos, pesquisas nessa linha irão enriquecer nossa visão de como a política era posta em prática (ou não), mas não quem estava a cargo dela.

Tradução: Fernanda Trindade Luciani

Recebido para publicação em agosto de 2009

Aprovado em setembro de 2009 